\title{
Determination of the best method to estimate glomerular filtration rate from serum creatinine in adult patients with sickle cell disease: a prospective observational cohort study
}

Jean-Benoît Arlet ${ }^{1}$, Jean-Antoine Ribeil ${ }^{2}$, Gilles Chatellier ${ }^{3}$, Dominique Eladari ${ }^{4}$, Sophie De Seigneux ${ }^{5}$, Jean-Claude Souberbielle ${ }^{6}$, Gérard Friedlander ${ }^{7}$, Marianne de Montalembert ${ }^{8}$, Jacques Pouchot ${ }^{1}$, Dominique Prié $^{6}$ and Marie Courbebaisse $e^{6,9^{*}}$

\begin{abstract}
Background: Sickle cell disease (SCD) leads to tissue hypoxia resulting in chronic organ dysfunction including SCD associated nephropathy. The goal of our study was to determine the best equation to estimate glomerular filtration rate (GFR) in SCD adult patients.

Methods: We conducted a prospective observational cohort study. Since 2007, all adult SCD patients in steady state, followed in two medical departments, have had their GFR measured using iohexol plasma clearance (gold standard). The Cockcroft-Gault, MDRD-v4, CKP-EPI and finally, MDRD and CKD-EPI equations without adjustment for ethnicity were tested to estimate GFR from serum creatinine. Estimated GFRs were compared to measured GFRs according to the graphical Bland and Altman method.
\end{abstract}

Results: Sixty-four SCD patients (16 men, median age 27.5 years [range 18.0-67.5], 41 with SS-genotype were studied. They were Sub-Saharan Africa and French West Indies natives and predominantly lean (median body mass index: $22 \mathrm{~kg} / \mathrm{m}^{2}$ [16-33]). Hyperfiltration (defined as measured GFR $>110 \mathrm{~mL} / \mathrm{min} / 1.73 \mathrm{~m}^{2}$ ) was detected in $53.1 \%$ of patients. Urinary albumin/creatinine ratio was higher in patients with hyperfiltration than in patients with normal GFR (4.05 mg/mmol [0.14-60] versus $0.4 \mathrm{mg} / \mathrm{mmol}$ [0.7-81], $p=0.01$ ). The CKD-EPI equation without adjustment for ethnicity had both the lowest bias and the greatest precision. Differences between estimated GFRs using the CKPEPI equation and measured GFRs decreased with increasing GFR values, whereas it increased with the CockcroftGault and MDRD-v4 equations.

Conclusions: We confirm that SCD patients have a high rate of glomerular hyperfiltration, which is frequently associated with microalbuminuria or macroalbuminuria. In non-Afro-American SCD patients, the best method for estimating GFR from serum creatinine is the CKD-EPI equation without adjustment for ethnicity. This equation is particularly accurate to estimate high GFR values, including glomerular hyperfiltration, and thus should be recommended to screen SCD adult patients at high risk for SCD nephropathy.

Keywords: Sickle cell disease, Glomerular hyperfiltration, Albuminuria, Glomerular filtration rate, CKD-EPI equation, lohexol plasma clearance, Ethnicity

\footnotetext{
* Correspondence: marie.courbebaisse@egp.aphp.fr

${ }^{6}$ Service d'Explorations Fonctionnelles. Faculté de médecine Paris Descartes,

INSERM U845 et Assistance publique -Hôpitaux de Paris, Hôpital Necker

Enfants Malades, 161, rue de Sèvres, 75015 Paris, Cedex 15, France, Paris

75908, France

${ }^{9}$ Hôpital Européen Georges Pompidou, 20, rue Leblanc, Cedex 15, Paris

75908, France

Full list of author information is available at the end of the article
} 


\section{Background}

Sickle cell disease (SCD) is one of the most common genetic hemoglobinopathies in which sickle hemoglobin leads to tissue hypoxia causing acute tissue damage and chronic organ dysfunction including SCD associated nephropathy [1]. Four genotypes-sickle cell anemia (HbSS), sickle-hemoglobin $\mathrm{C}$ disease (HbSC), and two types of sickle- $\beta$-thalassemia $(\mathrm{S} \beta+$-thalassemia and Sßo-thalassemia)_account for most cases of SCD. Compared to patients with other genotypes, those with a homozygous SS genotype have more profound anemia and higher morbidity and mortality [1,2]. SCD mainly affects natives of Sub-Saharan Africa, the West Indies, India, and South-America. Because of past and more recent migratory movements and thanks to better care in childhood, SCD has become a real health issue in European countries and especially in France where more than 7000 subjects are affected, half of whom are adults [2]. Glomerular hyperfiltration seems to be one of the first steps of SCD associated nephropathy, as in type I diabetes mellitus associated nephropathy [3], and is a frequent feature in young adult SCD patients $[4,5]$. Considering the negative impact of SCD associated nephropathy on the prognosis and the potential interest of an early nephroprotective treatment with angiotensin converting enzyme (ACE) inhibitors $[1,6,7]$, an accurate screening of glomerular hyperfiltration is essential. CKD-EPI, a new equation to estimate glomerular filtration rate (GFR) from serum creatinine, has been reported to be particularly accurate to estimate high levels of GFR [8] but has never been evaluated in SCD patients.

The main objective of our study was to determine the best equation to estimate GFR in SCD adult patients using five different equations. We also aimed at determining the prevalence of hyperfiltration and albuminuria among these patients and the relationship between albuminuria and GFR.

\section{Methods}

\section{Patients}

We conducted a prospective observational cohort study. Since January 2007, all newly referred SCD adult patients seen in two medical departments have had a comprehensive work-up including GFR measurement. At the time of investigation, all patients had to have been in steady state for at least three months (no acute illness, no vaso-occlusive crisis, no acute chest syndrome, and no urinary tract infection). Pregnant and breast feeding women, patients allergic to iodine, patients with diabetes mellitus, hypertension or other diseases susceptible to induce chronic kidney disease were not eligible for the present study. The study protocol conforms to the ethical guidelines of the 1975
Declaration of Helsinki and was approved by a local ethic committee (Comité de Protection des Personnes, Ile de France II) and received the number 2011531RCEB.

\section{Glomerular filtration rate measurement}

All patients underwent direct measurement of GFR using plasma clearance of iohexol, an exogenous marker, as previously described [9]. All patients received a $5 \mathrm{~mL}$ intravenous dose of iohexol. Each patient then simultaneously ingested $150 \mathrm{~mL}$ of water within 30 minutes. Blood samples were taken at 0,60, 120, 180, 240, and 300 minutes after injection. Clearance of iohexol was calculated by the following formula: Clearance $=$ Dose/ AUC, where AUC is the area under the plasma concentration curve.

Measured GFR (mGFR) was normalized in $\mathrm{mL} / \mathrm{mi}$ nute $/ 1.73 \mathrm{~m}^{2}$ by using the Dubois formula for the calculation of BSA (body surface area) [10].

$$
\operatorname{BSA}\left(\mathrm{m}^{2}\right)=0,0071184 \times \text { height }^{0,725} \times \text { weight }^{0,425}
$$

Since there is no consensus to define glomerular hyperfiltration we chose to define glomerular hyperfiltration as $\mathrm{mGFR}$ higher than $110 \mathrm{~mL} / \mathrm{min} / 1.73 \mathrm{~m}^{2}$, as did Haymann et al. [5].

\section{Biological measurements}

Other biological measurements included hemoglobin and reticulocyte counts, serum creatinine, and urinary albumin excretion rate (AER) on a single urinary spot expressed as $\mathrm{mg} / \mathrm{mmol}$ urinary creatinine. AER was categorized as normoalbuminuria (AER $<3 \mathrm{mg} / \mathrm{mmol}$ ), microalbuminuria (AER from 3 to $30 \mathrm{mg} / \mathrm{mmol}$ ), or macroalbuminuria (AER $>30 \mathrm{mg} / \mathrm{mmol}$ ). All measurements were made using standard hospital laboratory methods. Serum and urine creatinine were measured by using an alkaline picrate rate-blanked compensated kinetic assay (Hitachi 917 analyzer; Roche Diagnostics) with standardization to isotope dilution mass spectrometry.

\section{Equations used to estimate GFR MDRD-v4}

(Four variables Modification of Diet in Renal Disease equation) [11].

$$
\begin{aligned}
\operatorname{GFR} & \left(\mathrm{mL} / \mathrm{min} / 1.73 \mathrm{~m}^{2}\right)=175 \\
& \times\left\{[\text { plasma creatinine }(\mu \mathrm{mol} / 1) / 88.4]^{-1.154}\right\} \\
& \times \text { age }(\text { years })^{-0.203} \\
& \times 0.742(\text { if female }) \times 1.212(\text { if black })
\end{aligned}
$$




\section{MDRD without adjustment for ethnicity}

$$
\begin{aligned}
\text { GFR } & \left(\mathrm{mL} / \mathrm{min} / 1.73 \mathrm{~m}^{2}\right)=175 \\
& \times\left\{[\text { plasma creatinine }(\mu \mathrm{mol} / \mathrm{l}) / 88.4]^{-1.154}\right\} \\
& \times \text { age }(\text { years })^{-0.203} \times 0.742(\text { if female })
\end{aligned}
$$

\section{CKD-EPI [12]}

The CKD-EPI (Chronic Kidney Disease Epidemiology Collaboration) equation, expressed as a single equation, is: 'GFR $\left(\mathrm{mL} / \mathrm{min} / 1.73 \mathrm{~m}^{2}\right)=141 \times \min (\mathrm{Scr} / k, 1)^{\alpha} \times$ $\max (\mathrm{Scr} / k, 1)^{-1.209} \times 0.993^{\text {Age }} \times 1.018($ if female $) \times 1.159$ (if black), where Scr is serum creatinine, $k$ is 0.7 for females and 0.9 for males, $\alpha$ is -0.329 for females and -0.411 for males, min indicates the minimum of $\mathrm{Scr} / k$ or 1 , and max indicates the maximum of $\mathrm{Scr} / k$ or $1 . '$

\section{CKD-EPI without adjustment for ethnicity}

$$
\begin{aligned}
& \operatorname{GFR}\left(\mathrm{mL} / \mathrm{min} / 1.73 \mathrm{~m}^{2}\right)=141 \times \min (\mathrm{Scr} / k, 1)^{\alpha} \\
& \left.\times \max (\operatorname{Scr} / k, 1)^{-1.209} \times 0.993^{\text {Age }} \times 1.018 \text { (if female }\right)
\end{aligned}
$$

The MDRD-v4- and CKD-EPI-derived eGFRs with or without adjustment for ethnicity are expressed as $\mathrm{mL} /$ $\mathrm{min} / 1.73 \mathrm{~m}^{2}$ because the equations were derived by comparison with iothalamate-measured GFR, which itself is expressed as $\mathrm{mL} / \mathrm{min} / 1.73 \mathrm{~m}^{2}$.

\section{Modified Cockcroft-Gault [13]}

GFR $(\mathrm{mL} / \mathrm{min})$ for males $=[\mathrm{gX}(140-$ age $) \mathrm{X}$ weight $(\mathrm{kg})]$

$$
\text { /plasma creatinine }(\mu \mathrm{mol} / \mathrm{l}) \text {, }
$$

Where $g=1.23$ for males and 1.04 for females.

Estimated GFR derived by using the Cockcroft-Gault equation was converted from $\mathrm{mL} / \mathrm{min}$ to $\mathrm{mL} / \mathrm{min} /$ $1.73 \mathrm{~m}^{2}$ by multiplying calculated values by 1.73 , and dividing by BSA.

\section{Statistical methods}

Agreement between GFR estimated using the different equations described above and GFR measurement by iohexol plasma clearance (reference method) was assessed graphically by plotting the difference in GFR (estimated GFR - GFR measured by the reference method) against the mean GFR, where mean GFR is (GFR measured by the reference method + estimated GFR)/2), according to the method described by Bland and Altman [14]. Bias was estimated by the mean difference in GFR and limits of agreement defined by the mean difference \pm 1.96 standard deviations of the difference (SD).

Percentages were compared using the CHI-squared test, or the Fisher test, as appropriate.
Distributions were estimated using a kernel density distribution. Bandwith selection was done using the SheatherJones method [15]. Calculations were made using the the KDE procedure of the SAS statistical software.

Several means were compared using the KruskallWallis method (more than 2 groups) or the MannWhitney test (two groups). Differences were assessed using the paired t test. A p value less than 0.05 was considered significant.

In order to assess relationships between relevant quantitative variables, we used the Pearson correlation coefficient. Calculations were performed using the Statview Statistical and the SAS statistical software version 9.2.

\section{Results}

Description of the population and of SCD associated nephropathy

From January 2007 to December 2008, 67 consecutive adult SCD patients were studied. Three patients were excluded, including one with diabetes mellitus and two with hypertension. Finally, 64 patients were included in the present study: 41 with SS genotype, 15 with SC genotype, 7 with $\mathrm{S} \beta$ genotype, and 1 with SD genotype. Table 1 summarizes the main clinical and biological characteristics of the patients. They were predominantly young and lean (median body mass index (BMI): $22 \mathrm{~kg} /$ $\mathrm{m}^{2}$, range [16-33]). Most of them were native either of Sub-Saharan Africa or of the French West Indies.

Thirty-four patients (53.1\%) had hyperfiltration (defined as measured GFR (mGFR) $>110 \mathrm{~mL} / \mathrm{min} / 1.73 \mathrm{~m}^{2}$ ). Measured GFR non-indexed for BSA was comparable to mGFR expressed per BSA (mGFR non-indexed $\mathrm{BSA}=110.3 \mathrm{~mL} / \mathrm{min}$ (median, 26.8-167.9); mGFR expressed per $\mathrm{BSA}=112.5 \mathrm{~mL} / \mathrm{min} / 1.73 \mathrm{~m}^{2}(29-183)$; $\mathrm{p}=0.2$ ). Hyperfiltration was more common in patients with SS genotype than among those with non-SS genotype $(\mathrm{p}=0.0017)$ (Table 1$)$. Only one patient (a 48-yearold female with SC-genotype) had a GFR $<60 \mathrm{~mL} / \mathrm{min} /$ $1.73 \mathrm{~m}^{2}$. Microalbuminuria or macroalbuminuria were found in $36 \%$ and $14 \%$ of the patients, respectively. As shown in Table 1, the median urinary albumin/creatinine ratio was significantly higher in patients with hyperfiltration than in patients with normal or low mGFR (4.05 $\mathrm{mg} / \mathrm{mmol}$ [0.14-60] versus $0.4 \mathrm{mg} / \mathrm{mmol}$ [0.7-81], $\mathrm{p}=0.01$ ). As shown in Table 2 , when measured GFR is divided into quartiles, the median urinary albumin/creatinine ratio was the lowest for the second quartile of mGFR and significantly increased for mGFR above $112 \mathrm{~mL} / \mathrm{min} / 1.73 \mathrm{~m}^{2}(\mathrm{p}=0.029)$.

\section{Determination of the best equation to estimate GFR from} plasma creatinine in adult patients with SCD

Bland and Altman graphs are presented in Figure 1. In our adult SCD population, all equations overestimate 
Table 1 Characteristics of the studied population

\begin{tabular}{|c|c|c|c|c|}
\hline & $\begin{array}{l}\text { Whole population } \\
(n=64)\end{array}$ & $\begin{array}{l}\text { Patients with SS } \\
\text { genotype }(n=41)\end{array}$ & $\begin{array}{l}\text { Patients with non- } \\
\text { SS genotype }(n=23)\end{array}$ & $\begin{array}{l}p \text { value * SS vs } \\
\text { non-SS }\end{array}$ \\
\hline & $(n=64)$ & $(n=41)$ & $(n=23)$ & \\
\hline Sex ratio (M/F), (M\%) & $16 / 48(25.0 \%)$ & $11 / 30(27 \%)$ & $5 / 18(22 \%)$ & 0.22 \\
\hline Age, years & 27.5 [18-67.5] & $26.8[18-49.5]$ & $31.7[18-67.5]$ & 0.03 \\
\hline Ethnical origin & & & & 0.74 \\
\hline Sub Saharian Africa & $48(75 \%)$ & $32(78.1 \%)$ & $16(69.6 \%)$ & \\
\hline French West Indies & $10(15.6 \%)$ & $6(14.6 \%)$ & $4(17.4 \%)$ & \\
\hline Maghreb & $2(3.1 \%)$ & $1(2.4 \%)$ & $1(4.3 \%)$ & \\
\hline Other & $4(6.3 \%)$ & $2(4.9 \%)$ & $2(8.7 \%)$ & \\
\hline Height, m & $1.67[1.48-1.83]$ & $1.68[1.53-1.83]$ & $1.66[1.48-1.78]$ & 0.27 \\
\hline Weight, kg & $63[43.5-90]$ & $61.5[43.5-81]$ & $64[45-90]$ & 0.03 \\
\hline Body mass index, $\mathrm{kg} / \mathrm{m}^{2}$ & $22[16-33]$ & $21[16-30]$ & $24[16-33)]$ & 0.017 \\
\hline Hemoglobin, $\mathrm{g} / \mathrm{dL}$ & $8.9[5.5-14.3]$ & $8.2[5.5-12.6]$ & $10.7[7.5-14.3]$ & $<0.001$ \\
\hline Reticulocyte count, $\times 10^{3} / \mathrm{mm} 3$ & $170[32-466]$ & $219[32-466]$ & 99 [34-271] & $<0.001$ \\
\hline Plasma creatinine, $\mu \mathrm{mol} / \mathrm{L}$ & 55 [27-113] & $48[27-76]$ & $65[51-113]$ & $<0.001$ \\
\hline mGFR, $\mathrm{mL} / \mathrm{min} / 1,73 \mathrm{~m}^{2}$ & 112.5 [29-183] & 119 [65-183] & 98 [29-163] & $<0.002$ \\
\hline GFR $>110 \mathrm{~mL} / \mathrm{min} / 1,73 \mathrm{~m}^{2}$ & $34(53.1 \%)$ & $28(68.3 \%)$ & $6(26.1 \%)$ & 0,0017 \\
\hline Urinary albumin/creatinine, $\mathrm{mg} / \mathrm{mmol}$ & $2.87[0.07-134]$ & $4.84[0.14-80.6]$ & $0.63[0.07-134]$ & 0.005 \\
\hline No albuminuria $(<3 \mathrm{mg} / \mathrm{mmol})$ & $32(50 \%)$ & $16(39 \%)$ & $16(69.5 \%)$ & \\
\hline Microalbuminuria & $23(36 \%)$ & $17(41.5 \%)$ & $6(26.1 \%)$ & \\
\hline Macroalbuminuria (>30 mg/mmol) & $9(14 \%)$ & $8(19.5 \%)$ & $1(4.3 \%)$ & 0.053 \\
\hline
\end{tabular}

Results are expressed as numbers (\%) or median [range].

M: male, F: female,

mGFR: glomerular filtration rate measured by iohexol plasma clearance.

* Tests are either Chi-square or Fisher's exact test for categorical variables or Kruskall-Wallis test (more than two groups) or the Mann-Whitney test (two groups) for continuous variables.

GFR compared to mGFR by iohexol plasma clearance $(\mathrm{p}<0.05$, paired $\mathrm{t}$-test). Moreover, the wide limits of agreement (Table 3) suggest that large discrepancies between equations and mGFR can be observed. Distributions of measured GFR and estimated GFRs using a kernel density distribution were represented in Figure 2 and confirm this previous point. Compared to the Cockcroft and Gault and MDRD-v4 equations, the CKD-EPI equation had both the lowest bias and the narrowest limits of agreement. The difference between estimated GFR calculated with the CKD-EPI equation and mGFR decreases with increasing GFR values $(\mathrm{r}=-0.23$, $\mathrm{p}=0.06$ ). In addition, we observed a significant relationship between the difference and the mean for both the Cockcroft and Gault $(\mathrm{r}=0.34, \mathrm{p}<0.05)$ and the MDRD$v 4$ equations $(r=0.68, p<0.001)$. This means that the difference between estimated GFR and mGFR (gold standard) increases with increasing GFR values.

The MDRD-v4 and CKD-EPI equations comprise four variables: age, sex, plasma creatinine and White/AfricanAmerican ethnic group. The patients of our study population were mainly natives of Sub-Saharan African

Table 2 Urinary albumin/creatinine ratio according to measured glomerular filtration rate (mGFR) divided into quartiles

\begin{tabular}{|c|c|c|c|c|}
\hline mGFR & $\begin{array}{l}\text { Quartile range } \\
\left(\mathrm{mL} / \mathrm{min} / 1.73 \mathrm{~m}^{2}\right)\end{array}$ & Median within the quartile $\left(\mathrm{mL} / \mathrm{min} / 1.73 \mathrm{~m}^{2}\right)$ & Urinary albumin/creatinine ratio, (mg/mmol) & p value* \\
\hline Quartile 1 & {$[29-75]$} & 74.5 & $1.86[0.23-134.24]$ & 0.029 \\
\hline Quartile 2 & {$[96-112]$} & 105 & $0.405[0.07-80.63]$ & \\
\hline Quartile 3 & {$[113-128]$} & 119 & $3.04[0.14-31.47]$ & \\
\hline Quartile 4 & [129-183] & 145 & 8.43 [0.36-59.77] & \\
\hline
\end{tabular}

mGFR: glomerular filtration rate measured by iohexol plasma clearance.

Q1, Q2, Q3, Q4: each quartile of mGFR.

* $\mathrm{p}$ value was calculated using a Kruskal-Wallis test. Results are expressed as median [range]. 

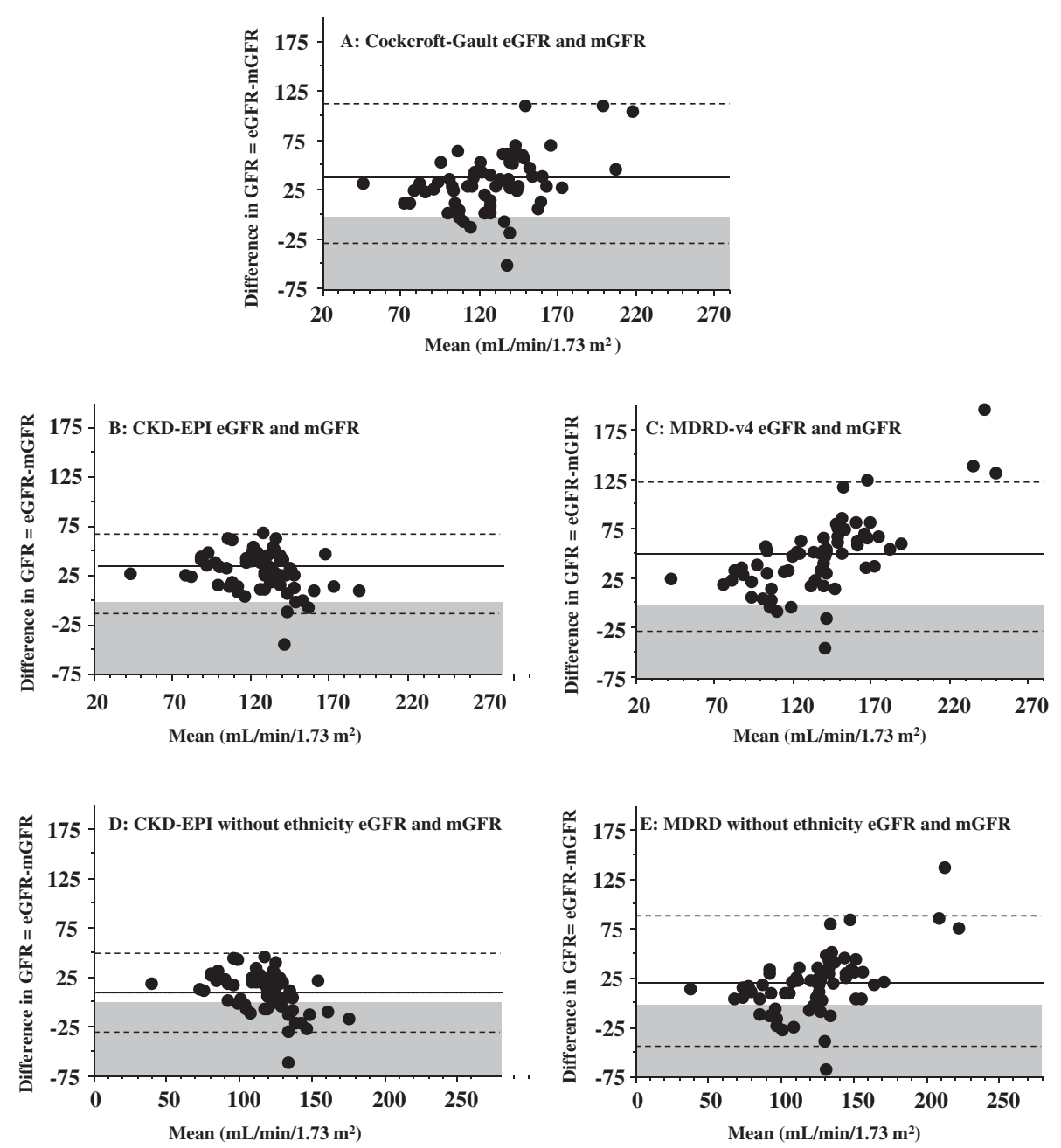

Figure 1 Bland and Altman plots for glomerular filtration rate (GFR) estimated with different equations compared to measured GFR. Each graph is a Bland and Altman plot comparing a specific equation used for GFR estimation to the reference method (GFR measured using iohexol plasma clearance). Mean GFR is calculated as follows: Mean GFR = (measured GFR + estimated GFR)/2. The plain line represents the mean difference between estimated GFR (eGFR) and GFR measured using the reference method (mGFR). In the grey zone, eGFR is lower than mGFR. Dashed lines represent $\pm 1.96 \mathrm{SD}$. Results are expressed as $\mathrm{mL} / \mathrm{min} / 1.73 \mathrm{~m}^{2}$.

countries and of the French West Indies. None of our patients was of African-American origin. Consequently, the adjustment for racial group was not considered appropriate for our population. Therefore, we removed ethnicity from these two equations. Without this variable (Figures 1D and 1E), overestimation decreased for both MDRD-v4 and CKD-EPI whereas limits of agreement remained comparable. Among the five equations tested to estimate GFR, the CKD-EPI equation without adjustment for ethnic group had both the lowest bias and the narrowest limits of agreement. Finally, for the CKD-EPI equation without adjustment for ethnic group, the difference with the gold standard decreased with increasing GFR values $(\mathrm{r}=-0.43, \mathrm{p}<0.001)$, whereas this difference increased for the MDRD equation without adjustment for ethnic group $(r=0.538, p<0.001)$.

\section{Discussion}

Our study shows that the CKD-EPI equation without the adjustment for African-American ethnicity is the best equation to estimate GFR from serum creatinine in adult SCD originating from Sub-Saharan Africa and the French West Indies. It also confirms the high prevalence of hyperfiltration among these patients and its association with increased urinary albumin excretion rate.

Recently, Haymann et al.. have reported that the MDRD-v4 equation was a more robust predictor of hyperfiltration compared to the Cockcroft and Gault estimated GFR in a cohort of adult SCD patients, although the MDRD-v4 equation systematically overestimated measured GFR [5]. In our study, we clearly show that the MDRD-v4 equation has both the highest bias and the lowest precision, followed by the Cockcroft and 
Table 3 Mean difference $(95 \% \mathrm{CI})$ and median difference [IQR] between each method of glomerular filtration rate (GFR) estimation and measured GFR

\begin{tabular}{|c|c|c|c|}
\hline \multirow[t]{2}{*}{ Method of estimation } & \multirow{2}{*}{$\frac{\text { Mean difference }}{\text { Median }}$} & \multirow{2}{*}{$\frac{95 \% \text { Confidence interval }}{[I Q R]}$} & \multirow{2}{*}{$\begin{array}{l}\mathrm{p} \\
\text { value* }\end{array}$} \\
\hline & & & \\
\hline \multirow[t]{2}{*}{ Cockcroft-Gault } & 45.3 & 26.8 to 41.3 & $<0.0001$ \\
\hline & 38.9 & {$[20.5-63.8]$} & \\
\hline \multirow[t]{2}{*}{ CKD-EPI } & 30.2 & $25.8 \mathrm{t} \circ 35.2$ & $<0.0001$ \\
\hline & 30.5 & {$[16.5-44.3]$} & \\
\hline \multirow[t]{2}{*}{ CKD-EPI without adjustment for ethnicity } & 10.7 & 5.8 to 15.7 & $<0.0001$ \\
\hline & 12.8 & {$[-0.7-24.8]$} & \\
\hline \multirow[t]{2}{*}{ MDRD-v4 } & 48.7 & 40.0 to 58.4 & $<0.0001$ \\
\hline & 49.3 & {$[24.7-64.8]$} & \\
\hline \multirow[t]{2}{*}{ MDRD without adjustment for ethnicity } & 20.7 & 12.9 to 28.5 & $<0.0001$ \\
\hline & 19.9 & {$[4.9-32.9]$} & \\
\hline
\end{tabular}

Results are expressed as $\mathrm{mL} / \mathrm{min} / 1.73 \mathrm{~m}^{2}$.

IQR: Inter Quartile Range.

CKD: Chronic Kidney Disease.

MDRD: Modification of Diet in Renal Disease.

CKD-EPI: Chronic Kidney Disease Epidemiology Collaboration.

* $\mathrm{p}$ value was calculated using a paired t-test.

Gault equation and lastly by the CKD-EPI equation, not assessed in the study by Haymann et al.. [5]. In the MDRD study $[11,16]$, the MDRD-v4 equation was found to be accurate in predicting GFR for values $<60 \mathrm{~mL} / \mathrm{min} / 1.73 \mathrm{~m}^{2}$ whereas the CKD-EPI equation was shown to be as accurate as MDRD in the subgroup with estimated GFR $<60 \mathrm{~mL} / \mathrm{min} / 1.73 \mathrm{~m}^{2}$ and substantially more accurate in the subgroup with estimated GFR $>60 \mathrm{~mL} / \mathrm{min} / 1.73 \mathrm{~m}^{2}$ $[12,17,18]$. The better performance of the CKD-EPI equation in this specific SCD population is thus expected at least in part because many such patients have normal or high GFR [12].

We also showed that both the MDRD-v4 and the CKD-EPI equations gave better estimation of GFR after excluding the correction for ethnicity. Finally, among the five equations tested, the CKD-EPI equation without adjustment for ethnicity was the most accurate to estimate GFR in our population. The correction of estimated GFR for black people by multiplying estimated GFR by 1.212 for the MDRD-v4 equation [11] and by

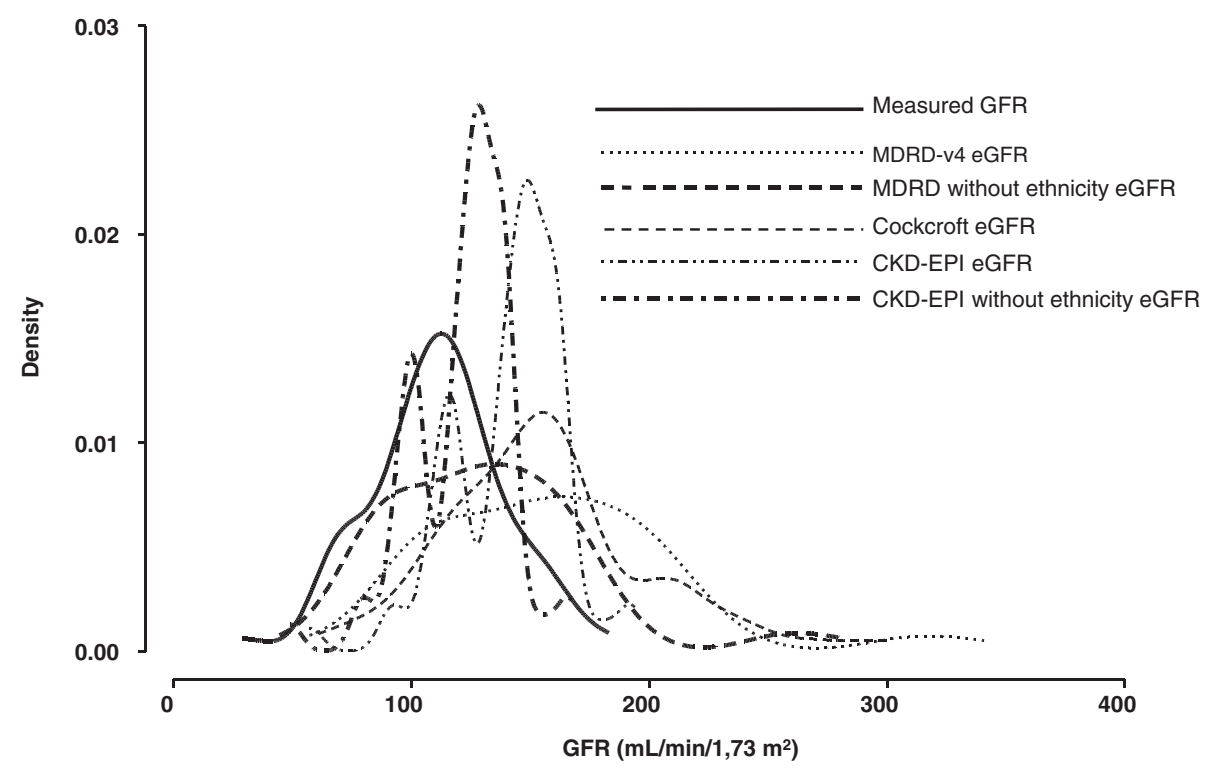

Figure 2 Distributions of measured GFR and estimated GFRs using a kernel density distribution. CKD: Chronic Kidney Disease; CKD-EPI: Chronic Kidney Disease Epidemiology Collaboration; eGFR: estimated GFR; GFR: Glomerular Filtration rate; MDRD: Modification of Diet in Renal Disease. Results of GFR are expressed as $\mathrm{mL} / \mathrm{min} / 1.73 \mathrm{~m}^{2}$. 
1.159 for the CKD-EPI equation [12] is based on studies performed in African-Americans. It has not been validated in black people of other ethnic origin, nor at extremes of body weight [8]. It has recently been shown that the CKD-EPI equation without adjustment for ethnicity is the most useful equation to estimate GFR in a lean Sub-Saharan African population [19] which may share some characteristics with adult SCD populations. Moreover, in a study of one hundred black South Africans, Van Deventer et al.. have reported that both the MDRD-v4 [20] and the CKD-EPI [21] equations overestimated GFR when using the ethnicity correction factor as suggested for African-Americans. Among the patients they studied, fifteen had a BMI $<20 \mathrm{~kg} / \mathrm{m}^{2}$ and their median weight and BSA were $67 \mathrm{~kg}$ and $1.75 \mathrm{~m}^{2}$ respectively. In our study, the unexpected improvement of the performance of the MDRD and CKD-EPI equations without adjustment for ethnicity to estimate GFR could be explained by the fact that our patients had lower BMI compared to the one of the patients tested in MDRD and CKD-EPI samples since the mean body weight was $79.6 \mathrm{~kg}$ in the MDRD study [11] and $82 \mathrm{~kg}$ in the CKDEPI study [12]. Another explanation could be that meat intake [22] may be lower in our population than in the African-American one. It was also shown that AfricanAmericans had greater serum creatinine levels and urinary creatinine excretion for any given GFR compared to non-African-Americans [23]. Finally, the MDRD and CKD-EPI equations were developed in patients with chronic kidney disease stage $4-5$. The study of Peralta et al.. [24] strongly suggests that even in a cohort of African-American, the race correction factors of 1.21 for the MDRD-v4 et 1.16 for the CKD-EPI equations are probably too high for young patients with CKD-EPI estimated GFR comprised between 60 and $80 \mathrm{~mL} / \mathrm{min} /$ $1.73 \mathrm{~m}^{2}$ and should rather be 1.12 .

Determining the best equation for GFR estimation is of great importance, especially for the care of SCD patients living in developing areas where GFR measurement is not easily accessible. Our results, as well as those of other studies [19,21], claim for the use of more specific equations to estimate GFR according to the subpopulation tested. Most online formulas for calculating estimated GFR using the MDRD-v4 or CKD-EPI equations propose to choose between "black skin" and "non black skin" or between "African origin" and "nonAfrican origin", whereas they should offer the choice of "African-American" versus "non- African-American origin”.

In the case of SCD patients, screening for GFR level and especially for glomerular hyperfiltration status is of paramount importance, given its association with microalbuminuria or macroalbuminuria [5,25,26]. As previously explained, we chose to define glomerular hyperfiltration as mGFR higher than $110 \mathrm{~mL} / \mathrm{min} /$ $1.73 \mathrm{~m}^{2}$, as did Haymann et al. [5]. Using this controversial definition, glomerular hyperfiltration seems to be a very frequent finding in young adult SCD patients: in our study, $68 \%$ of patients with SS-genotype had glomerular hyperfiltration, similar to the $66 \%$ of 48 homozygous SCD patients reported previously for whom GFR was measured using urinary ${ }^{51} \mathrm{Cr}$ EDTA method [5]. Moreover, in our patients' population, we demonstrated that the urinary albumin/creatinine ratio significantly increased when $\mathrm{mGFR}$ was above $112 \mathrm{~mL} / \mathrm{mn} / 1.73 \mathrm{~m}^{2}$. Since we showed that mGFR non-indexed for BSA was comparable to mGFR expressed per BSA, we can assert that the putative hyperfiltration status is not an artifact linked to BSA indexation in our population. Indeed BSA indexation is questionable especially in subjects with low BMI $[27,28]$. However, both the MDRD and CKDEPI equations automatically estimate GFR expressed per BSA, so that we could not express estimated and measured GFRs without this indexation.

One of the limitations of our study could lie in the lack of homogeneity of our population since we chose to pool the SCD patients with SS and non-SS genotypes. However, although the patients with hemoglobin SS had a more severe disease than those with other sickling hemoglobinopathies, the measurement properties of the five equations tested were similar in SCD patients with or without the SS genotype. Ideally, the validity of the CKD-EPI equation without the adjustment for AfricanAmerican ethnicity should have been assessed in a control group comprising individuals of the same ethnic origin but with an AA genotype test to allow us to claim that hyperfiltration was specific to SCD but this last point was not the main goal of our study. Moreover, Thompson et al.. already have already shown that SCD patients have higher GFR as well as higher urinary albumin to creatinine ratio than controls [29].

Another limitation of our study is the definition of hyperfiltration. We chose to consider that a measured GFR higher than $110 \mathrm{~mL} / \mathrm{min} / 1.73 \mathrm{~m}^{2}$ defines hyperfiltration for two reasons: first, this definition is the one given by Haymann et al.. in their recent work about GFR in SCD patients [5] and we wished to compare our results to theirs; secondly, although this arbitrary level may be considered as too low, we observed that in our population, urinary albumin excretion was the lowest when mGFR was between 96 and $112 \mathrm{~mL} / \mathrm{min} / 1.73 \mathrm{~m}^{2}$, whereas urinary albumin excretion significantly increased when mGFR was higher than $112 \mathrm{~mL} / \mathrm{min} / 1.73 \mathrm{~m}^{2}$. Consequently a mGFR higher than $110 \mathrm{~mL} / \mathrm{min} / 1.73 \mathrm{~m}^{2}$ may be considered as pathological in this population as it is more frequently associated with the presence of micro or macroalbuminuria. 


\section{Conclusions}

Our study confirms that SCD patients have a high rate of glomerular hyperfiltration, which is frequently associated with microalbuminuria or macroalbuminuria and shows that in SCD patients of non African-American origin, the CKD-EPI equation without adjustment for ethnicity should be the recommended method to estimate GFR.

\section{Abbreviations}

ACE: angiotensin converting enzyme; AER: albumin excretion rate; BMI: body mass index; BSA: body surface area; CKD: chronic kidney disease; eGFR: estimated glomerular filtration rate; mGFR: measured glomerular filtration rate; SCD: sickle cell disease CKD: Chronic Kidney Disease; MDRD: Modification of Diet in Renal Disease; CKD-EPI: Chronic Kidney Disease Epidemiology Collaboration.

\section{Competing interests}

The authors declare that they have no competing interests.

\section{Authors' contributions}

J-B A contributed to patients' recruitment, to acquisition and interpretation of data and to the manuscript preparation. J-A R and J P contributed to patients' recruitment and to the manuscript preparation. G C performed statistical analysis and contributed to the manuscript preparation. D E and D P performed GFR measurements and contributed to interpretation of data. S D S contributed to the manuscript preparation. J-C S and G F contributed to acquisition and interpretation of data. M C performed GFR measurement, contributed to acquisition and interpretation of data and wrote the manuscript. All authors gave final approval of the present version.

\section{Author details}

${ }^{1}$ Service de Médecine Interne, centre de référence des syndromes drépanocytaires majeurs, Faculté de médecine Paris Descartes et Assistance publique - Hôpitaux de Paris, Hôpital Européen Georges Pompidou, Cedex 15, Paris 75908, France. ${ }^{2}$ Département de Biothérapie, centre de référence des syndromes drépanocytaires majeurs, Faculté de médecine Paris Descartes et Assistance publique - Hôpitaux de Paris, Hôpital Necker Enfants Malades, 161, rue de Sèvres, 75015 Paris Cedex 15, Paris, France 75908, France. ${ }^{3}$ Faculté de médecine Paris Descartes et CIC-EC4 INSERM, Assistance publique - Hôpitaux de Paris, Hôpital Européen Georges Pompidou, Cedex 15, Paris 75908, France. ${ }^{4}$ Service d'Explorations Fonctionnelles. Faculté de médecine Paris Descartes, INSERM U872 et Assistance publique -Hôpitaux de Paris, Hôpital Européen Georges Pompidou, 20, rue Leblanc, Cedex 15, Paris 75908, France. ${ }^{5}$ Service de Néphrologie, Hôpital Cantonal de Genève, 4 rue Perret Gentil, Genève 4, Suisse 1211, Switzerland. ${ }^{6}$ Service d'Explorations Fonctionnelles. Faculté de médecine Paris Descartes, INSERM U845 et Assistance publique -Hôpitaux de Paris, Hôpital Necker Enfants Malades, 161, rue de Sèvres, 75015 Paris, Cedex 15, France, Paris 75908, France. ${ }^{\text {SService }}$ d'Explorations Fonctionnelles. Faculté de médecine Paris Descartes, INSERM U845 et Assistance publique -Hôpitaux de Paris, Hôpital Européen Georges Pompidou, 20, rue Leblanc Cedex 15, Paris 75908, France. ${ }^{8}$ Service de Pédiatrie Générale, Assistance publique -Hôpitaux de Paris, Hôpital Necker Enfants Malades, 161, rue de Sèvres, 75015 Paris, Cedex 15, France, Paris 75908, France. ${ }^{9}$ Hôpital Européen Georges Pompidou, 20, rue Leblanc, Cedex 15, Paris 75908, France.

Received: 7 June 2012 Accepted: 28 July 2012

Published: 6 August 2012

\section{References}

1. Falk RJ, Scheinman J, Phillips G, Orringer E, Johnson A, Jennette JC: Prevalence and pathologic features of sickle cell nephropathy and response to inhibition of angiotensin-converting enzyme. N Engl J Med 1992, 326:910-915.

2. Bardakjian J, Benkerrou M, Bernaudin F, et al: Travail du Groupe sur le dépistage néonatal de la drépanocytose: Neonatal screening of sickle cell anemia in metropolitan France. Arch Pediatr 2000, 7:1261-1263.
3. Guasch A, Navarrete J, Nass K, Zayas CF: Glomerular involvement in adults with sickle cell hemoglobinopathies. Prevalence and clinical correlates of progressive renal failure. J Am Soc Nephro. 2000, 7:1261-1263.

4. Barros FB, Lima CS, Santos AO, et al: 51Cr-EDTA measurements of the glomerular filtration rate in patients with sickle cell anaemia and minor renal damage. Nucl Med Commun 2006, 27:959-962.

5. Haymann JP, Stankovic K, Levy P, et al: Glomerular hyperfiltration in adult sickle cell anemia: a frequent hemolysis associated feature. Clin J Am Soc Nephrol 2010, 5:756-761.

6. Aoki RY, Saad ST: Enalapril reduces the albuminuria of patients with sickle cell disease. Am J Med 1995, 98:432-435.

7. Foucan $L$, Bourhis $V$, Bangou J, Mérault L, Etienne-Julan M, Salmi RL: A randomized trial of captopril for microalbuminuria in normotensive adults with sickle cell anemia. Am J Med 1998, 104:339-342.

8. Florkowski CM, Chew-Harris JS: Methods of Estimating GFR - Different Equations Including CKD-EPI. Clin Biochem Rev 2011, 32:75-79.

9. Gaspari F, Perico N, Ruggenenti P, et al: Plasma clearance of nonradioactive iohexol as a measure of glomerular filtration rate. J Am Soc Nephrol 1995, 6:257-263.

10. DuBois D, DuBois EF: A formula to estimate the approximate surface area if height and weight are known. Arch Intern Med 1916, 17:863-871.

11. Levey AS, Bosch JP, Lewis JB, Greene T, Rogers N, Roth D: A more accurate method to estimate glomerular filtration rate from serum creatinine: a new prediction equation. Modification of Diet in Renal Disease Study Group. Ann Intern Med 1999, 130:461-470.

12. Levey AS, Stevens LA, Schmid CH, et al: CKD-EPI (Chronic Kidney Disease Epidemiology Collaboration): A new equation to estimate glomerular filtration rate. Ann Intern Med 2009, 150:604-612.

13. Cockcroft DW, Gault MH: Prediction of creatinine clearance from serum creatinine. Nephron 1976, 16:31-41.

14. Bland JM, Altman DG: Statistical methods for assessing agreement between two methods of clinical measurement. Lancet 1986, 8:307-310.

15. Sheather SJ, Jones MC: A reliable data-based bandwidth selection method for kernel density estimation. Journal of the Royal Statistical Society series B 1991, 53:683-690.

16. Froissart M, Rossert J, Jacquot C, Paillard M, Houillier P: Predictive performance of the modification of diet in renal disease and CockcroftGault equations for estimating renal function. J Am Soc Nephrol 2005, 16:763-773

17. Stevens LA, Schmid $\mathrm{CH}$, Greene T, et al: Comparative performance of the CKD Epidemiology Collaboration (CKD-EPI) and the Modification of Diet in Renal Disease (MDRD) Study equations for estimating GFR levels above $60 \mathrm{~mL} / \mathrm{min} / 1.73 \mathrm{~m} 2$. Am J Kidney Dis 2010, 56:486-495.

18. Winearls CG, Lamb EJ: Chronic kidney disease: the CKD-EPI equation to estimate GFR-better alchemy? Nat Rev Nephrol 2011, 7:127-128.

19. Eastwood JB, Kerry SM, Plange-Rhule J, et al: Assessment of GFR by four methods in adults in Ashanti, Ghana: the need for an eGFR equation for lean African populations. Nephrol Dial Transplant 2010, 25:2178-2187.

20. van Deventer HE, George JA, Paiker JE, Becker PJ, Katz IJ: Estimating glomerular filtration rate in black South Africans by use of the modification of diet in renal disease and Cockcroft-Gault equations. Clin Chem 2008, 54:1197-1202.

21. van Deventer HE, Paiker JE, Katz IJ, George JA: A comparison of cystatin $C$ - and creatinine-based prediction equations for the estimation of glomerular filtration rate in black South Africans. Nephrol Dial Transplant 2011, 26:1553-1558.

22. Preiss DJ, Godber IM, Lamb EJ, Dalton RN, Gunn IR: The influence of a cooked-meat meal on estimated glomerular filtration rate. Ann Clin Biochem 2007, 44:35-42.

23. Lewis J, Agodoa L, Cheek D, et al: Comparison of cross-sectional renal function measurements in African Americans with hypertensive nephrosclerosis and of primary formulas to estimate glomerular filtration rate. Am J Kidney Dis 2001, 38:744-753.

24. Peralta CA, Lin F, Shlipak MG, et al: Race differences in prevalence of chronic kidney disease among young adults using creatinine-based glomerular filtration rate-estimating equations. Nephrol Dial Transplant 2010, 25:3934-3939.

25. Schmitt F, Martinez F, Brillet $G$, et al: Early glomerular dysfunction in patients with sickle cell anemia. Am J Kidney Dis 1998, 32:208-214.

26. Wesson DE: The initiation and progression of sickle cell nephropathy. Kidney Int 2002, 61:2277-2286. 
27. Turner ST, Reilly SL: Fallacy of indexing renal and systemic hemodynamic measurements for body surface area. Am J Physiol 1995, 268:978-988.

28. Delanaye P, Krzesinski JM: Indexing of renal function parameters by body surface area: intelligence or folly? Nephron Clin Pract 2011, 119:289-292.

29. Thompson J, Reid M, Hambleton I, Serjeant GR: Albuminuria and renal function in homozygous sickle cell disease: observations from a cohort study. Arch Intern Med 2007, 167:701-708.

doi:10.1186/1471-2369-13-83

Cite this article as: Arlet et al: Determination of the best method to estimate glomerular filtration rate from serum creatinine in adult patients with sickle cell disease: a prospective observational cohort study. BMC Nephrology 2012 13:83.

\section{Submit your next manuscript to BioMed Central and take full advantage of:}

- Convenient online submission

- Thorough peer review

- No space constraints or color figure charges

- Immediate publication on acceptance

- Inclusion in PubMed, CAS, Scopus and Google Scholar

- Research which is freely available for redistribution 